At best, it may be legitimately used of the hypo. thetical major groups (for example, black, white and yellow) into which we deduce that our species early became differentiated, and which may be called primary races ; and of the equally hypothetical subgroups apparently produced by later differentiation (for example, Nordic, Alpine or Mediterranean), which may be called secondary races.

Ar the present day, there exists no important human group which can properly be called a race, and the use of the term not only has no useful application, but actually leads to confusion, both scientific and political. For groups of people genetically distinguishable from other groups, some noncommittal term like ethnic group or ethnos is indicated. Ethnic groups of various degrees of difference will be distinguished; the only scientific method of so doing is to take the mean, the frequency curves, and the conditions of several measurable physical char. acters. For the common adjectival use of racial as opposed to national, cultural, etc., the terms ethnic or genetic should be used, according to circumstances. To define race in man scientifically is impossible, since the implications of the term do not conform with reality. Meanwhile, since the word race has been widely used in a pseudo-scientific way to justify and rationalise various political and nationalist activities, it is highly desirable that an international inquiry should be made which would result in an impartial scientific pronouncement on the subject.

\section{Defence Against Air Raids}

Ir is announced that the committee set up in February 1935, under the chairmanship of Mr. H. T. Tizard, Rector of the Imperial College of Science and Technology, has been considering proposals from various sources for countering raids by enemy aircraft. The vast bulk of these suggestions are impracticable simply because of a lack of appreciation of the conditions. A certain number are workable up to a point, but depend upon the enemy being visible from the ground, or upon the defending aircraft being able to make contact with the attackers. Two factors in modern aeronautical development tend to militate these chances. Advances in navigation and blind flying enable raiders to remain continuously in clouds, with a reasonable chance of reaching their objective. If observed, owing to an unexpected breaking of the cloud curtain, the high speed of modern aircraft helps them to avoid any measures directed against them from the ground, and also to keep away from defending aircraft, unless the latter are already at the same height and of considerably greater speed. There are, however, schemes in hand which promise workable results. Wireless. controlled aircraft either carrying explosives or depending upon direct collision, aerial bombs moored by balloons or carried by parachutes forming a screen, mechanical damaging devices such as rams, hooks or wires carried in the same way, big calibre anti-aircraft guns firing shells sufficiently explosive to damage machines even without actually hitting them, are among the many suggestions put forward.

\section{The 200-inch Reflector}

IT is stated by the New York correspondent of The Times that the 200-inch disk began its 3,300-mile railway journey from Corning, New York, to Pasadena on March 26. It is encased in a steel crate weighing 10 tons, with the face of the disk protected by a 4-inch blanket of cork, and its rim by five layers of heavy felt, and is being carried on edge in a specially designed truck. The weight of the crated disk is supported by steel beams covered with cushions of compressed cork. The accompanying illustration (Fig. 1), reproduced from the article by Dr. George E. Hale on the 200-inch telescope which was

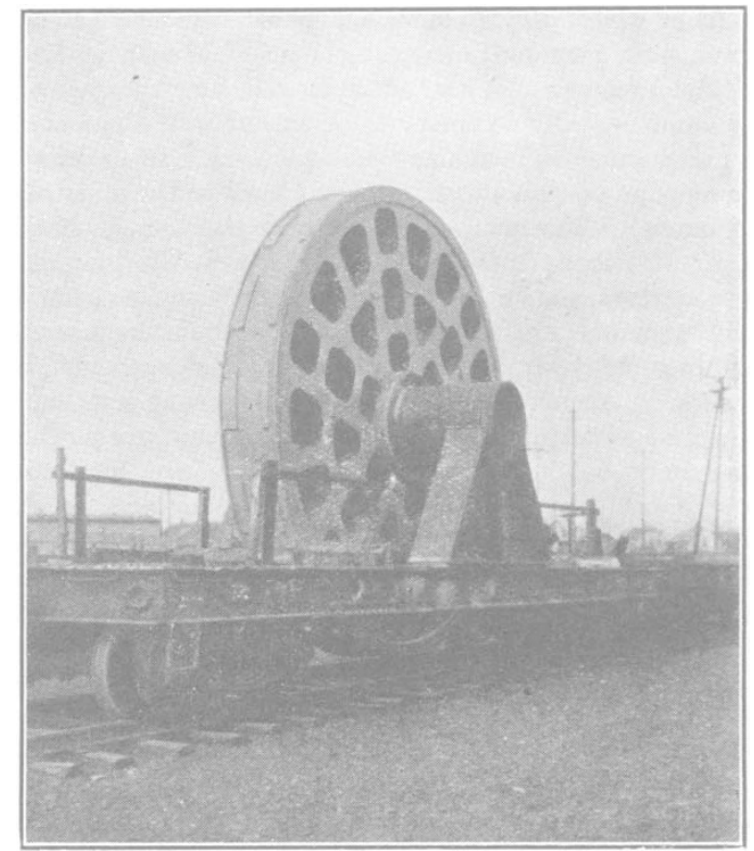

FIG. 1. Base of tube for 200 -inch telescope.

published as a Supplement to Nature of February 8 , will bring home better than words the transport difficulties involved. The train will not travel faster than 25 miles an hour; the greatest care will have to be exercised, because the bottom edge of the crate is only six inches above the level of the rails, and at certain tunnels and bridges the top will have a clearance of only three inches. The news of the safe arrival of the disk at Palomar Mountain will be awaited with anxiety.

\section{Sir Patrick Laidlaw, F.R.S.}

Sir Patrick Laidiaw has been appointed by the Medical Research Council to be deputy director of the National Institute for Medical Research, and head of the Department of Pathology and Bacteriology, in succession to the late Capt. S. R. Douglas. Sir Patrick has been a member of the Council's scientific staff at the National Institute since 1922, before which he was lecturer in pathology at Guy's Hospital. He received the Royal Medal of the Royal Society in 1933, and was knighted in 1935. $\mathrm{He}$ has latterly been engaged chiefly in the investigation of diseases 